\title{
Forcing factors of cloud-to-ground lightning over Iberia: regional-scale assessments
}

\author{
J. A. Santos ${ }^{1}$, M. A. Reis ${ }^{1}$, F. De Pablo ${ }^{2}$, L. Rivas-Soriano ${ }^{2}$, and S. M. Leite ${ }^{1}$ \\ ${ }^{1}$ Centre for the Research and Technology of Agro-environmental and Biological Sciences, \\ University of Trás-os-Montes e Alto Douro, Vila Real, Portugal \\ ${ }^{2}$ Departamento de Física General y de la Atmósfera, University of Salamanca, Salamanca, Spain
}

Correspondence to: J. A. Santos (jsantos@utad.pt)

Received: 26 November 2012 - Published in Nat. Hazards Earth Syst. Sci. Discuss.: Revised: 3 May 2013 - Accepted: 28 May 2013 - Published: 5 July 2013

\begin{abstract}
Cloud-to-ground lightning in a sector covering the Iberian Peninsula, the Balearic Islands and nearby seas (36$\left.44^{\circ} \mathrm{N}, 10^{\circ} \mathrm{W}-5^{\circ} \mathrm{E}\right)$ is analysed in the period from 2003 to 2009 (7 yr). Two Iberian lightning detection networks, composed of 18 sensors over Portugal and Spain, are combined for the first time in the present study. The selected characteristics are cloud-to-ground flashes (CGFs), first stroke peak current, polarity and multiplicity (number of strokes in a given flash). This study examines the temporal (on hourly, monthly and seasonal timescales) and spatial variability of CGFs. The influence of five forcing factors on lightning (elevation, lifted index, convective available potential energy and daily minimum and maximum near-surface air temperatures) over the Iberian sector is also assessed. For regional-scale assessments, six subsectors with different climatic conditions were analysed separately. Despite important regional differences, the strongest lightning activity occurs from late spring to early autumn, and mostly in the afternoon. Furthermore, CGFs are mainly located over high-elevation areas in late spring to summer, while they tend to occur over the sea in autumn. The results suggest that (1) orographically forced thunderstorms over mountainous areas, mostly from May to September, (2) tropospheric buoyancy forcing over westerncentral and northern regions in summer and over the Mediterranean regions in autumn, and (3) near-surface thermal contrasts from October to February largely control the location of lightning in Iberia. There is no evidence of different forcings by polarity. A clear correspondence between summertime precipitation patterns and CGFs is also found.
\end{abstract}

\section{Introduction}

The Iberian Peninsula, due to its extent, topography, soil heterogeneity and geographical location, exhibits intense lightning activity. In the 1990s, soon after the installation of the Spanish lightning detection network (LDN), which is maintained by the Spanish Meteorological Office (Agencia Estatal de Meteorología - AEMET), scientific research on lightning activity over the Iberian Peninsula started. This observational network provides the location of lightning flashes based on their electric and magnetic properties (e.g. Rakov and Uman, 2003; Poelman, 2010). The corresponding sensors (IMPACT $141 \mathrm{~T}$ and IMPACT ES) are similar to those installed in many other LDNs, such as in the United States. For a more detailed development of this methodology, readers are referred to Orville and Huffines (1999), Cummins et al. (1998) and Pérez-Puebla (2004).

A similar technology has also been installed in the Portuguese LDN, which is maintained by the Portuguese Meteorological Office (Instituto Português do Mar e da Atmosfera - IPMA). This network comprises four detectors that have been operating since June 2002 (Carvalho et al., 2003; Rodrigues et al., 2008). Both the location of the sensors and the equipment were designed to complement the Spanish LDN (Fig. 1). This warrants a common observational system for the two institutions (AEMET and IPMA), which brings important advantages concerning the location accuracy and detection efficiency of lightning strokes in both countries. More recently, the European Cooperation for Lightning Detection (EUCLID; http://www.euclid.org/) project has aimed to establish a united LDN over most of Europe. 


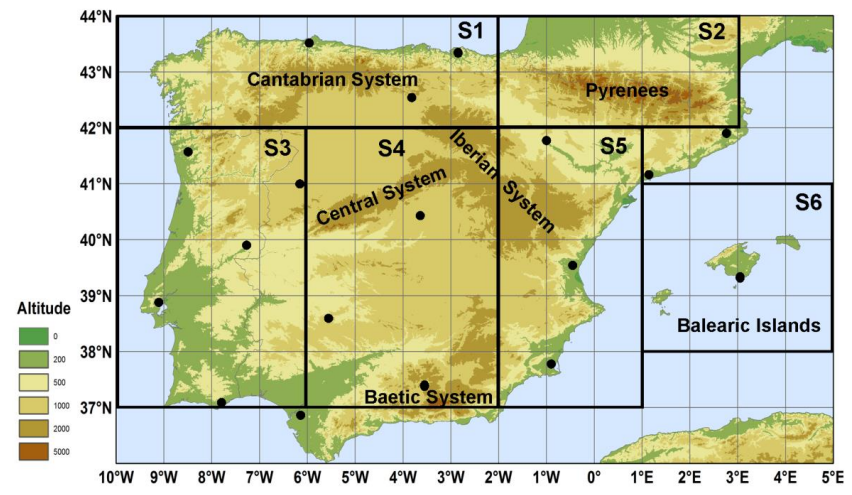

Fig. 1. Lightning detection network in the Iberian Peninsula with 14 IMPACT sensors in Spain and 4 IMPACT sensors in Portugal. Black circles indicate the geographical locations of the 18 sensors. The six selected subsectors (S1-6) in the Iberian sector (IS: 36$44^{\circ} \mathrm{N}, 10^{\circ} \mathrm{W}-5^{\circ} \mathrm{E}$ ), the orography (altitude in metres) and the main mountain ranges are also depicted.

The present study focuses on the analysis the cloud-toground flashes (CGFs) over a sector $\left(36-44^{\circ} \mathrm{N}, 10^{\circ} \mathrm{W}-5^{\circ} \mathrm{E}\right)$ covering the entire Iberian Peninsula, the Balearic Islands and nearby seas (Iberian sector - IS). This new dataset combines the two existing databases generated by the Spanish (AEMET) and Portuguese (IPMA) LDNs, resulting in an integrated database for the whole of Iberia.

The spatial and temporal characteristics of CGFs over Spain were analysed by Soriano et al. (2005). Their results revealed a high correlation between orography and the distribution of CGFs (on a $0.2^{\circ} \times 0.2^{\circ}$ grid). Tomas et al. (2004) performed a classification of circulation weather types related to the daily CGF occurrences in Iberia (1992-1994). Soriano et al. (2004) and De Pablo and Soriano (2007) studied the wintertime North Atlantic Oscillation (NAO) forcing on CGFs in the Iberian Peninsula. Ramos et al. (2011) analysed the CGFs over Portugal for a $7 \mathrm{yr}$ period (2003-2009), focusing mainly on the variability of the CGF temporal and spatial distributions, as well as their correlation with elevation and topography. Santos et al. (2012) examined the largescale atmospheric forcing mechanisms on CGF occurrences, including the underlying lightning regimes.

A number of studies have been conducted in order to assess the role of soil characteristics in conducting electrical discharges, including elevation parameters (e.g. Dissing and Verbyla, 2003), temperatures (e.g. Altaratz et al., 2003; Pinto and Pinto, 2008; Tinmaker et al., 2010), land use (e.g. Rozoff et al., 2003), type of vegetation (e.g. Carleton et al., 2008), fire effects (e.g. Kilinc and Beringer, 2007), lake effects (e.g. Steiger et al., 2009), among others. Soriano et al. (2001a) highlighted the important role played by the orographic forcing on lightning activity in Castile and León (Spain). Owing to the very high complexity of the orographic features of the Iberian Peninsula, which are accompanied by strong climatic contrasts between the northwestern regions (with pronounced Atlantic influence) and the eastern coastal areas (with strong Mediterranean influence) the main forcing factors of lightning are diverse.

As lightning activity is physically related to deep convection, significant relationships between the number of CGFs and convective activity, in particular its forcing factors, is expected. Therefore, an important forcing factor of lightning is orography, as orographically forced deep convection is closely linked to thunderstorms. The initiation of deep convection is often associated with low-level convergence zones of different origins (Fankhauser et al., 1995). In particular, thermally induced local winds, like slope and mountain winds, generate convergence zones upstream and downstream of mountains that can potentially trigger deep convective development (Kunz and Wassermann, 2011; Toth and Johnson, 1985; Kalthoff et al., 2009). This is particularly noteworthy over the Iberian Peninsula, where orography is rather complex, with several mountain ranges and highelevation plateaus surrounded by water surfaces (Fig. 1). Several indices have been proposed to measure the likelihood of severe thunderstorms under a given temperaturehumidity vertical profile (e.g. Kunz, 2007). Among them, LI and CAPE are widely recognized as key indicators of the strength of the convective activity and are also used herein as forcing factors of lightning activity. As LI is an estimate of the net buoyancy force at $500 \mathrm{hPa}$ (negative upwards), its opposite value tends to be positively correlated with deep convection and thunderstorm development. CAPE provides a quantitative estimate of vertically integrated buoyancy and it is also an estimate of the updraft strength (Holton, 2004). Near-surface thermal contrasts may also be important forcing factors of thunderstorms through the generation of baroclinic instability and deep convection (Peixoto and Oort, 1992). Therefore, the minimum (TN) and maximum (TX) $2 \mathrm{~m}$ air temperatures are also tested as potential forcing factors of lightning activity in the IS, since they tend to represent nearsurface nocturnal and midday conditions, respectively. Five potential forcing factors are tested in the present study: elevation (Elev), best four-layer lifted index (LI), convective available potential energy (CAPE) and daily minimum (TN) and maximum (TX) $2 \mathrm{~m}$ air temperatures. Further, in order to characterize the seasonality of the relationship between lightning and precipitation in the IS, the precipitation totals (RR) are also taken into account. However, since precipitation is not a driving mechanism of lightning, but rather a possible manifestation of convective activity, it is thus not included in the set of the five forcing factors mentioned above.

Therefore, the present study aims at isolating some of these forcings and to assess their relative importance on a seasonal/monthly basis. This information may also be of key relevance for improving weather forecasting across the region. In this manner, the temporal (on hourly, monthly and seasonal timescales) and spatial distributions of CGFs are analysed and correlated with the aforementioned five forcing 
factors. Section 2 describes the selected datasets, including the Iberian lightning dataset, and the followed methodology. Section 3 presents and discusses the temporal and spatial variability of CGFs and their correlations with the five forcing factors. Finally, Sect. 4 presents the main conclusions of the present study.

\section{Data and methods}

The characteristics of CGFs in the IS are herein analysed in the period from 2003 to 2009 (7 yr) and using a dataset that combines the Spanish and Portuguese LDNs. This Iberian LDN is composed of 18 IMPACT (IMProved Accuracy Through Combined Technology) sensors (14 in Spain and 4 in Portugal). This network employs three methods to locate lightning flashes: time of arrival, direction and a combination of the two. The time of arrival is based on the time lapse in the detection of electromagnetic radiation by different sensors. The direction is detected by a triangulation method, thus using at least three sensors (Cummins et al., 1998). The flash detection efficiency in Spain has improved in the last years, increasing from about $70 \%$ in 1992 up to $90 \%$ by 2001 (Pérez-Puebla, 2004). Worth noting is that the detection efficiency does not exclusively depend on the distance to the sensors (Schulz et al., 1998; Schulz et al., 1996). On the other hand, the precision in stroke location has increased from an error of $3 \mathrm{~km}$ to $0.5 \mathrm{~km}$ in the same period over mainland Spain. Although the efficiency over mainland Portugal is lower, it has enhanced from $50 \%$ in 1992 to $80 \%$ in 2001 (Pérez-Puebla, 2004). Despite some uncertainty due to several maintenance problems, the 2001 values remain nearly unchanged up to the present, as well as during the studied period (2003-2009). The joint efficiency of flash detection in the Iberian LDN is nearly $90 \%$ for strokes with peak currents higher than $5 \mathrm{kA}$ and over the entire peninsula (Rodrigues et al., 2010).

Apart from the time of occurrence of the lightning flashes (UTC in year, month, day, hour, minute and second) and their location (latitude and longitude in degrees with four decimal places), first stroke peak current (in kA) and polarity (positive or negative), and multiplicity (number of strokes that constitute a given flash) are also provided. The raw datasets are available in text files, where each detected flash corresponds to a single line with all the specifications referred to above. In the present study, raw data are interpolated into a gridded dataset on an hourly basis. The number of CGFs by polarity, average peak current and average multiplicity are defined on a $0.1^{\circ} \times 0.1^{\circ}$ grid (spatial resolution of about $10 \mathrm{~km}$, typical size of ordinary thunderstorms) over IS, with 81 latitudes $\times 151$ longitudes (12231 grid boxes). The same gridded parameters are also computed on a daily basis from hourly data.

The number of CGFs, total and by polarity, is related to the five potential forcing factors mentioned above (Elev,
LI, CAPE, TN, and TX). The gridded Elev dataset (altitude in metres) is obtained from the global digital elevation model GTOPO30 of the Earth Resources Observation and Science (EROS) Center (http://eros.usgs.gov/), with a grid spacing of approximately $1 \mathrm{~km}$. The LI dataset from the National Centers for Environmental Prediction Final Operational Model Global Tropospheric Analyses (NCEP FNL) is supplied by the University Corporation for Atmospheric Research (UCAR; http://rda.ucar.edu/datasets/ds083.2/) and is available at a spatial resolution of $1.0^{\circ}$ latitude $\times 1.0^{\circ}$ longitude and at $6 \mathrm{~h}$ intervals. The CAPE dataset are obtained from the European Centre for Medium-range Weather Forecasts (ECMWF) ERA-Interim reanalysis (Dee et al., 2011) and are available on a $1.5^{\circ} \times 1.5^{\circ}$ grid and at $6 \mathrm{~h}$ intervals. As will be shown below, most of the CGFs occur in the afternoon. As such, only the instantaneous fields at 12:00 and 18:00 UTC are extracted for LI and CAPE; the four daily instantaneous fields (00:00, 06:00, 12:00 and 18:00 UTC) were also tested separately, but the results were in general less significant than using 12:00-18:00 UTC means (not shown). The gridded daily TN, TX and RR from the E-OBS dataset (Haylock et al., 2008), produced by the EU-FP6 project ENSEMBLES (http://ensembles-eu.metoffice.com), are provided by the European Climate Assessment \& Dataset (ECA\&D) project (http://eca.knmi.nl). The original gridded data is defined only over land areas in Europe on a $0.25^{\circ} \times 0.25^{\circ}$ grid and is herein extracted for the IS.

Monthly means of LI, CAPE, TN, TX, and RR are computed on their original grids and, along with elevation, are bilinearly interpolated to the CGF grid $\left(0.1^{\circ}\right.$ latitude $\times 0.1^{\circ}$ longitude) within the IS. The $7 \mathrm{yr}(2003-2009)$ means of these variables are then spatially (point-by-point) correlated with the corresponding monthly numbers of CGFs in the period from 2003 to 2009 . As the distributions are in general non-Gaussian, the non-parametric Spearman rank correlation is used (Wilks, 2011); their statistical significance is assessed at $5 \%$ level. The analysis is also undertaken separately for positive- and negative-polarity CGFs.

The analysis of the temporal-spatial variability of the CGFs and of their forcing factors is undertaken for the whole of Iberia and for six non-overlapping subsectors within the IS (Fig. 1): north (S1), Pyrenees (S2), western Iberia (S3), central Iberia (S4), eastern Iberia (S5) and Balearic Islands (S6). This procedure enables a better characterization of the diurnal and seasonal lightning cycles in each region, as well as a better differentiation of the lightning forcing factors amongst regions. The choice of the different subsectors was based on both the annual mean distribution of the CGFs, already discussed by previous studies (e.g. Soriano et al., 2005), and the main climatic characteristics in the Iberian Peninsula (e.g. Leite and Santos, 1998; Santos and Mendes, 2009; Santos and Santos, 2009). The set of six subsectors do not entirely cover the peninsula, leaving out the southern coast of Andalusia and parts of Catalonia. However, their particular climatic features do not allow their inclusion in the chosen 


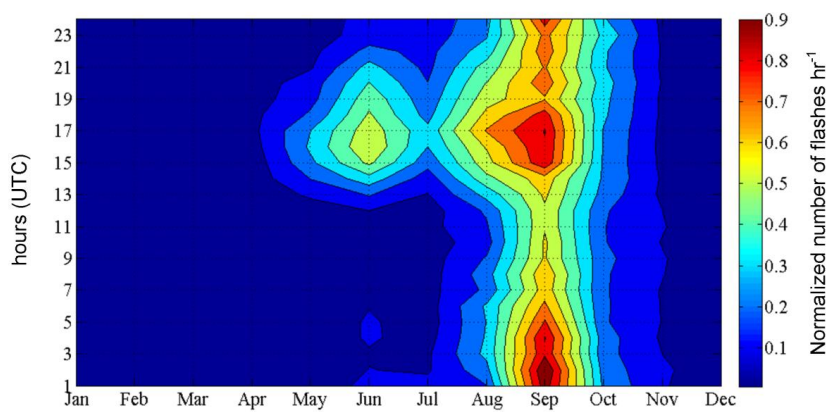

Fig. 2. Hour-month diagram of the hourly CGF totals recorded within the Iberian sector (IS: $36-44^{\circ} \mathrm{N}, 10^{\circ} \mathrm{W}-5^{\circ} \mathrm{E}$ ) and averaged over the $7 \mathrm{yr}$ baseline period (2003-2009). Values are normalized to unit maximum.

subsectors and are, at the same time, not large enough to be considered separately; the sample sizes become excessively short and do not ensure the statistical robustness of the results. A sensitivity study was carried out testing different sets of subsectors, but the main results remain largely unchanged.

\section{Results}

\subsection{Temporal variability}

The hourly CGF totals (in flashes $\mathrm{h}^{-1}$ ) recorded within the IS are calculated for each month separately and averaged over the $7 \mathrm{yr}$ baseline period (2003-2009). The corresponding normalized (to unit maximum) values are displayed in an hour-month diagram (Fig. 2); this normalization allows a comparison with other similar diagrams for different subsectors. This diagram shows strong seasonal and diurnal cycles, with an important concentration of the lightning activity in relatively narrow periods of the year and of the day. The overall distribution reveals a maximum occurrence in September and a secondary peak in June. Few flashes (weak activity) occur in the period from November to April, the winter half of the year, a result that can also be extended to other regions, such as for Estonia (Enno, 2011). In September, the daily cycle shows high CGF occurrences from 15:00 to 05:00 UTC, revealing a long diurnal period with strong activity, but peaking at 02:00 and 17:00 UTC. In June there is a clear incidence of CGF occurrences in the afternoon, from 15:00 to 18:00 UTC.

The corresponding hour-month diagrams for each of the six selected sections are displayed in Fig. 3. For both the northern sector (S1, Fig. 3a) and Pyrenees (S2, Fig. 3b), the CGF occurrences reveal a preference of occurring in the warm months (June-August) and in the afternoon, with a bi-modal distribution, peaking in June or in August, respectively. In S1, the maximum of CGF occurrences in June is recorded between 15:00 and 17:00 UTC, while in S2 the largest number of CGF occurrences in August hints at a broad maximum from 15:00 to 20:00 UTC. In western Iberia (S3, Fig. 3c), the strongest activity is found in September, whereas a weaker maximum is found in May. In both cases activity is stronger from 16:00 to 18:00 UTC, which is in clear agreement with Santos et al. (2012). In central Iberia (S4, Fig. 3d), two clear maxima are identified (June and September), with maximum CGF occurrences between 15:00 and 19:00 UTC in June, and slightly earlier in September (14:00 to 17:00 UTC). The lightning activity in eastern Iberia (S5, Fig. 3e) is mainly in August-September, with a weaker maximum in June. The peaks of CGF occurrences are remarkable in August-September, particularly during the afternoon (16:00 to 18:00 UTC). Lastly, the Balearic Islands (S6, Fig. 3f), with more maritime conditions, depict a predominant peak in September, between 01:00 and 05:00 UTC, and experience very low activity in the afternoon, which is a noteworthy difference when compared to other sectors/regions. Similar results were found by Gladich et al. (2011) and Enno (2011) in the daily cycle of CGFs over the south of the Alps and Estonia, respectively. These studies also found that coastal regions present higher nocturnal lightning activity than inland areas, which is in accordance with the diurnal cycle for the Balearic Islands.

Convective activity in the Iberian Peninsula is mainly (but not only) associated with warm-air convection (Soriano and De Pablo, 2002). This explains that most of lightning activity is observed around 17:00 UTC from May to September (Figs. 2 and 3). Nonetheless, in July, the influence of the Azores high pressure system in suppressing convection (by large-scale subsidence) is apparent over most of the peninsula, particularly over its southwestern regions (S3 and S4), which are the most exposed to its direct influence. Furthermore, northern Iberia is usually affected by Atlantic synoptic disturbances, which may account for the pronounced maximum detected in June over that area (S1, Fig. 3a). In fact, as the Azores anticyclone is not yet fully consolidated, it allows the arrival of cold-core mid-latitude disturbances when surface temperature is already rather high, generating atmospheric instability.

For the Balearic Islands there is no evidence for the bimodal distribution observed in the other regions (Fig. 3f). As the Balearic Islands are less exposed to the influence of the Azores high pressure system, there is no clear split between late spring and early autumn activity, though spring activity is indeed very low. In fact, eastern Iberia and the Balearic Islands are deeply influenced by the Mediterranean Sea. The highest sea surface temperature (SST) values in September significantly enhance moisture availability and, when accompanied by upper-tropospheric troughs, may trigger thunderstorms and extreme precipitation events over the western Mediterranean (e.g. Pinto et al., 2013). Therefore, the thermodynamic atmospheric background over the Mediterranean areas of Iberia is more appropriate for deep convection in September (Soriano and De Pablo, 2002). Moreover, maritime convection is typically at its maximum in nocturnal 
(a)

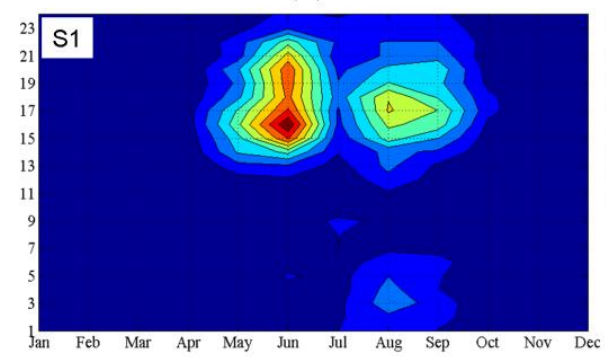

(c)

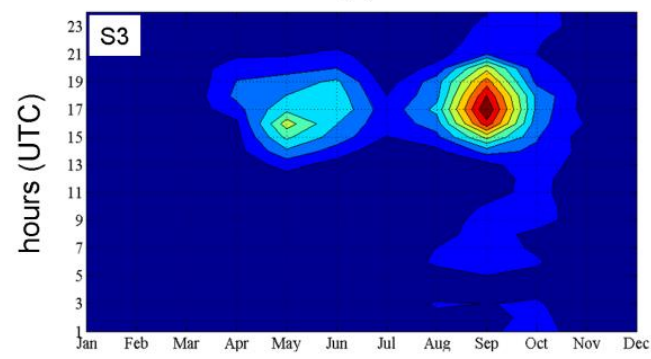

(e)

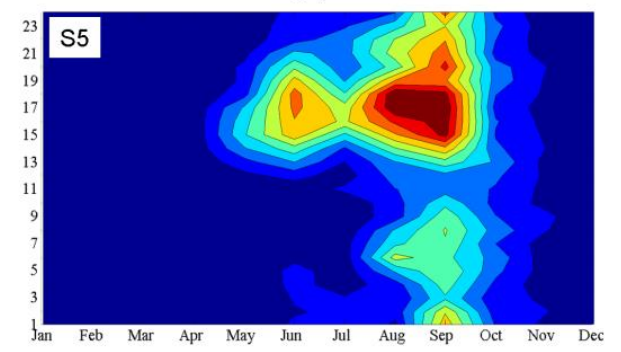

(b)

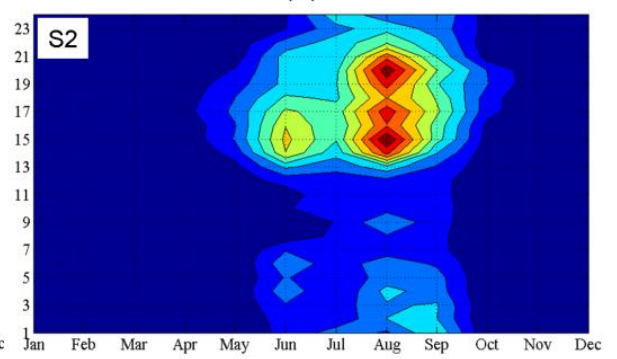

(d)
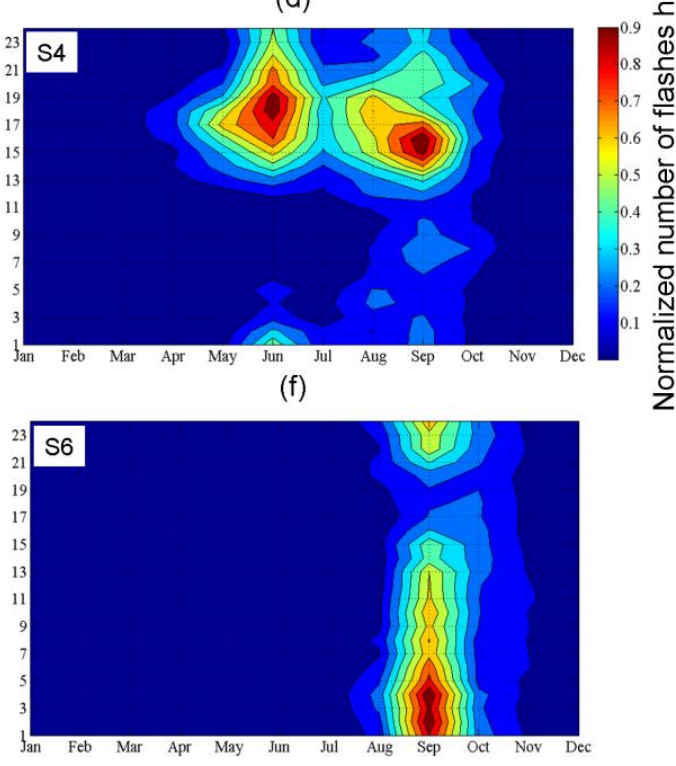

Fig. 3. As in Fig. 2, but now for the following subsectors in IS (cf. Fig. 1): (a) north (S1), (b) Pyrenees (S2), (c) western Iberian (S3), (d) central Iberia (S4), (e) eastern Iberia (S5), and (f) Balearic Islands (S6). Values are normalized to unit maximum in each diagram.

hours, both over the western and eastern Mediterranean Sea (De Pablo and Soriano, 2002; Altaratz et al., 2003), as well as over other maritime areas like the Pacific (Orville et al., 1997) and the Indian Ocean (Hidayat and Ishii, 1998). Several factors may contribute to this maximum, namely convergence of land breezes over the sea or convergence of prevailing large-scale westerly winds with continental land breezes (Altaratz et al., 2003). Therefore, areas with dominant water surface, such as S6, commonly present maximum lightning activity in the early morning. This characteristic is much less pronounced in S5 (Fig. 3e), because the ground surface is greater than the maritime surface and lightning activity tends to concentrate over land masses (Christian et al., 2003). Further, S5 includes part of the Iberian mountain range (Fig. 1), which enhances lightning activity over land mass. It should be noted that lightning activity over a particular island may show two peaks, since land areas near coastline are influenced by both land and sea. This fact has been found, for example, on the islands of Mallorca (De Pablo and Soriano, 2002) and Java (Hidayat and Ishii, 1998).

\subsection{Spatial variability}

The spatial distribution of CGF occurrences in the IS not only highlights the already mentioned large seasonality, but also its spatial heterogeneity (Fig. 4). Overall, within the IS, a high number of CGF occurrences is found in summer (JuneAugust, JJA) and autumn (September-November, SON), whereas much lower occurrences are observed in spring (March-May, MAM), and particularly in winter (DecemberFebruary, DJF). More specifically, in winter, the occurrence of lightning activity is generally weak over the entire peninsula, though with some scattered activity over the Mediterranean Sea (Fig. 4a). This result is an indication of the contrasting conditions found over land and sea surfaces in winter, as the former tend to be much cooler than the latter (i.e. low temperatures often inhibit deep convection). During spring (Fig. 4b), however, there is already significant lightning activity over the peninsula, mainly over mountain ranges, with a maximum over the Iberian System. The low activity levels recorded over the inner plateaus are worth mentioning, since their flat orography is not favourable for deep convection and thunderstorm development when 
(a)

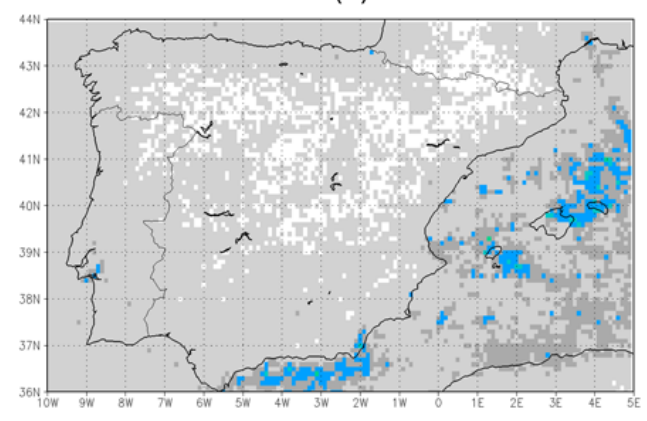

(c)

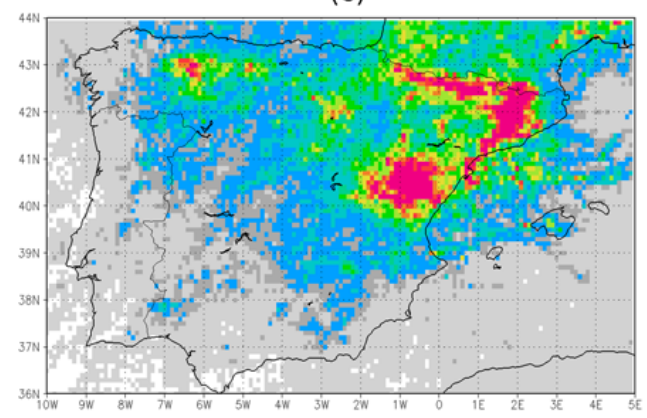

(b)

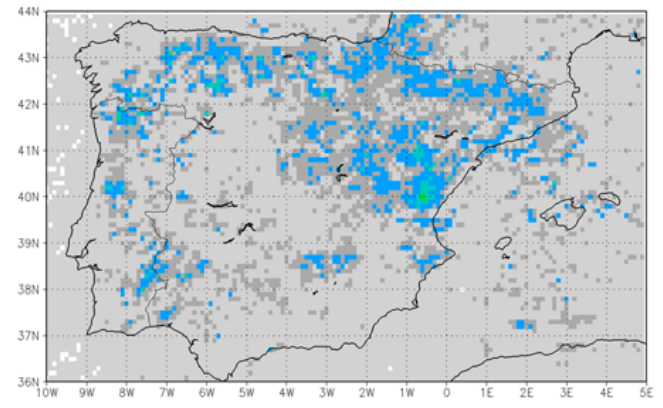

(d)

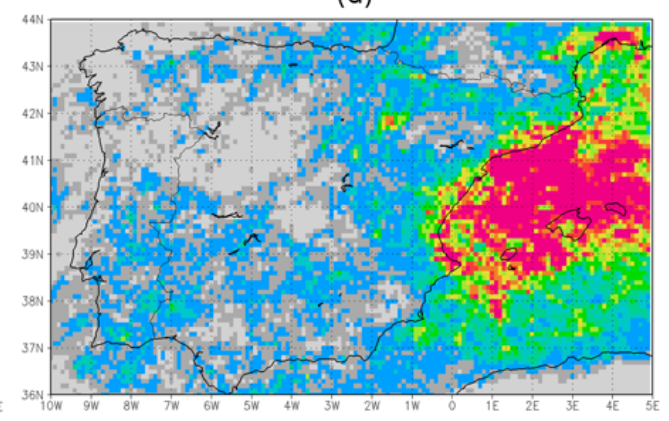

flashes day ${ }^{-1}$

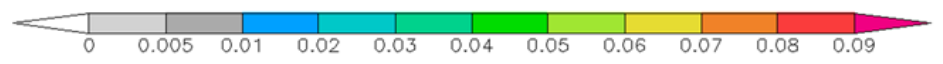

(e)

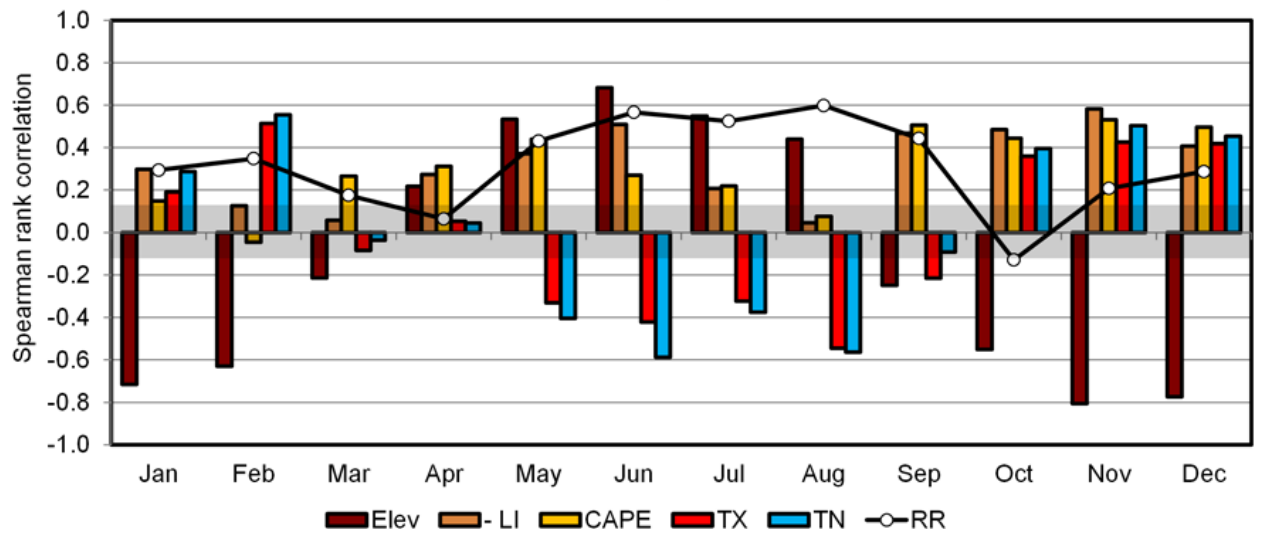

Fig. 4. Maps of the $7 \mathrm{yr}$ (2003-2009) (a) DJF, (b) MAM, (c) JJA, and (d) SON means of the daily CGFs (flashes day ${ }^{-1}$ ) recorded within the

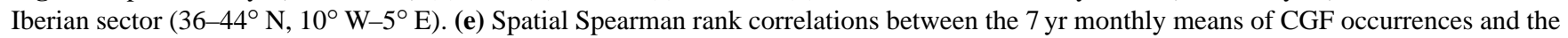
selected five forcing factors: elevation (Elev), monthly means of the opposite of the lifted index (-LI), convective available potential energy (CAPE), and daily minimum (TN) and maximum (TX) $2 \mathrm{~m}$ air temperatures. The correlations with the monthly precipitation totals (RR) are also displayed (black line). Grey shading indicates the $95 \%$ confidence interval of non-statistically significant correlations.

compared to the encircling mountain ranges (cf. Fig. 1). Conversely, low activity is observed over the sea surfaces.

The thunderstorm activity is significantly enhanced in summer (Fig. 4c), with the highest CGF occurrences found over mountainous areas in northern-northeastern Iberia, such as over the Pyrenees and the Iberian System (Fig. 4c). Furthermore, very low activity is found over southernsouthwestern Iberia, which is in line with the aforementioned clear separation between lightning activity in late spring and early autumn over these regions (Fig. 3c and d). Secondary peak occurrences are also found over the Cantabrian and Central systems (Fig. 4c). In autumn, a noteworthy shift in the location of the maximum activity area is clear, when maximum CGF occurrences are found over the Mediterranean Sea and the Balearic Islands (Fig. 4d). This strong lightning activity in the Mediterranean can be explained by higher minimum temperatures over the Mediterranean than over inner Iberia, which can also be related to the nocturnal maximum 
of CGF occurrences in S6 (Fig. 3f). These seasonal patterns are indeed corroborated by the spatial distribution of annual mean CGF density in Spain (Soriano et al., 2005).

Along the previous lines, it can be concluded that the spatial distribution of CGFs (Fig. 4a-d) is clearly driven by orographic features and land-sea thermal contrasts. These results are also supported by Kumar and Kamra (2012) in their study for southern and southeastern Asia. In studies carried out by de Souza et al. (2009) and by Kumar and Kamra (2010), for Brazil and India, respectively, the key role played by mountainous areas in triggering lightning activity is highlighted. In fact, convection initiation over complex terrain is commonly associated with a combination of different mechanisms that interact on different temporal and spatial scales, which can ultimately lead to deep convection (Corsmeier et al., 2011).

The role of the aforementioned five forcing factors on lightning activity in IS will now be examined in greater detail by considering the spatial correlations between the $7 \mathrm{yr}$ means of the monthly CGF patterns (not shown) and the corresponding patterns for each forcing (Fig. 4e).

The correlations with elevation show a maximum in June $(+0.7)$ and a minimum in November $(-0.8)$. These results reflect that CGF occurrences are mainly located over highelevation areas (positive correlation with elevation) during summer, while they tend to occur over sea surfaces (negative correlation with elevation) in autumn and winter. Correlations with elevation are relatively low in spring. Hence, the orographic forcing plays a key role in the location of CGFs, which is particularly clear in summer. These results are in agreement with Soriano et al. (2001a) in their study for Spain. In effect, the convective processes over complex ground surfaces are significantly different from those that originated over flat terrain. In fact, a number of studies have found that mountains tend to enhance convective activity (e.g. Tian and Parker, 2002; Stein, 2004; Barthlott et al., 2006). Vertical velocities were found to be higher over the summits than over flat terrain (Founda et al., 1997). Homar et al. (2003) reported that mountain breezes favour mesocyclogenesis by flow convergence over mountain ridges. Local wind systems leading to convergence zones may also be important for the initiation of convection over mountainous areas (Raymond and Wilkening, 1980). Furthermore, Pielke (2001) found that discontinuities in sensible heat flux can generate mesoscale circulations, which may trigger deep convection mechanisms over highland areas, even under weak synoptic flows (Hanesiak et al., 2004). In winter, however, when frontal thunderstorms are the main driving mechanism for lightning activity in the Iberian Peninsula, orography is not a relevant factor for deep convection, which is approximately homogeneously distributed throughout the day (Soriano et al., 2001b).

The correlations for - LI and CAPE reveal quite similar behaviours across the year (Fig. 4e). The highest values for both parameters are found in autumn (above +0.4 ), peaking in November $(+0.6)$. For the rest of the year, the values remain relatively low, ranging from nearly 0 to +0.4 . Hence, tropospheric buoyancy plays an important role in triggering lightning activity within the IS as a whole, particularly in autumn. In fact, as a large amount of the autumn CGFs are detected over the Mediterranean and the Balearic Islands, it can be concluded that tropospheric buoyancy is a significant factor in triggering thunderstorms over these areas. The coastal zones in the western Mediterranean region are favourable for the development of mesoscale convective systems due to low-level flow of humid and warm air combined with the presence of a large-scale trough over France and Spain, especially in autumn (Romero et al., 1999; Cohuet et al., 2011).

With respect to the near-surface air temperatures (TX and $\mathrm{TN}$ ), a strong agreement is found between them, with positive correlations from October to February and negative from May to September (Fig. 4e). No significant correlations can be found in March and April. This suggests that near-surface air temperature patterns in autumn and winter, and their spatial contrasts, tend to govern the spatial distribution of the CGFs, while in summer the negative correlations with TN and TX are mostly an indirect effect of the elevation forcing, as high-elevation areas are cooler. Hence, it can be stated that orographic effects in the warmer months (May-September), tropospheric buoyancy in autumn, and convergence zones that develop in the cooler months (October-February) play a key role in the location of thunderstorms within the IS.

Although precipitation is not a forcing factor, it is an important parameter associated with thunderstorms, especially in the case of convective precipitation. Owing to the relevance of this climatic element, its association with lightning is also investigated here. The correlations with the CGF patterns disclose some correspondence between precipitation and the CGF patterns (positive correlations throughout the year), mainly in the warmer period of the year (MaySeptember), when most of the CGFs occur (Fig. 2), with correlations ranging from 0.4 to 0.6 . This result suggests that precipitation is mostly convective in these periods of strong lightning activity.

The spatial distributions of positive-polarity CGFs, and the corresponding correlations with the five forcing factors and precipitation, are displayed in Fig. 5. As the spatial distributions of the negative-polarity CGFs are very similar to the patterns shown in Fig. 4, they are not presented here. Moreover, the numbers of positive-polarity CGFs are much lower than their negative counterparts (note the same colour scales in Figs. 4 and 5), which is in agreement with previous studies for the Iberian Peninsula (e.g. Soriano et al., 2005; Santos et al., 2012). However, the spatial patterns of the positive-polarity CGFs are similar to those of the total CGFs, which explains the close correspondence between their forcing factor correlations (Figs. $4 \mathrm{e}$ and 5e). Nevertheless, the forcing factor correlations for the positive-polarity CGFs tend to be slightly lower than for the total CGFs. This can be partially explained by the significantly lower number 
(a)

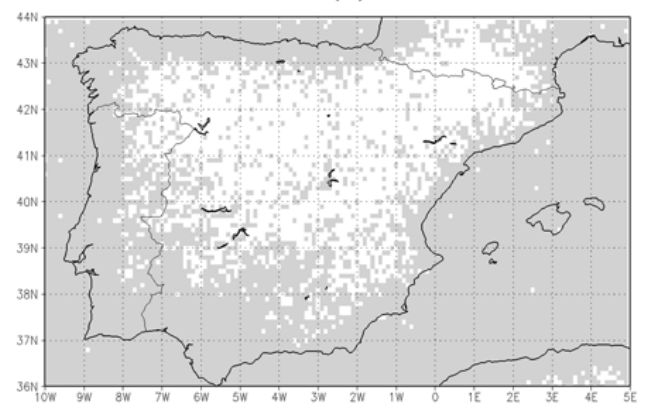

(c)

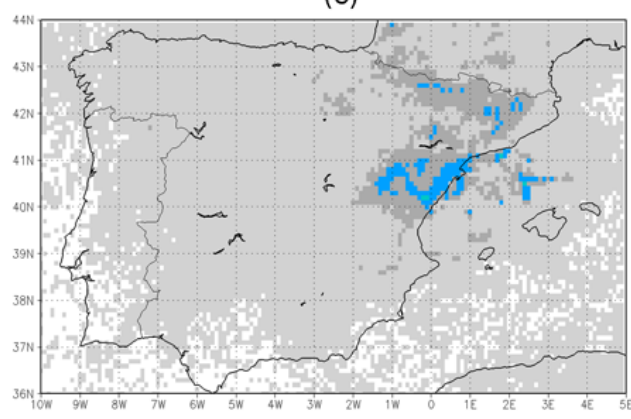

(b)

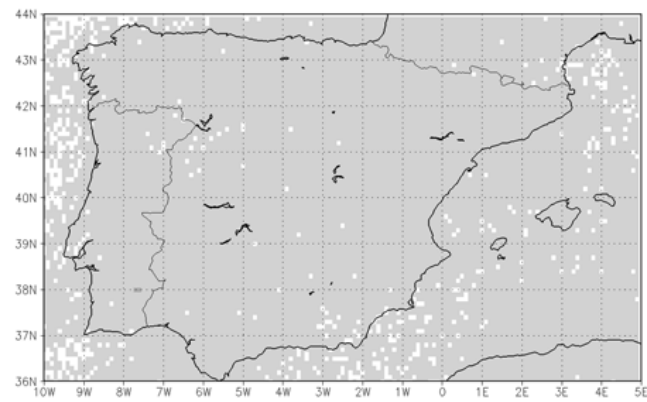

(d)

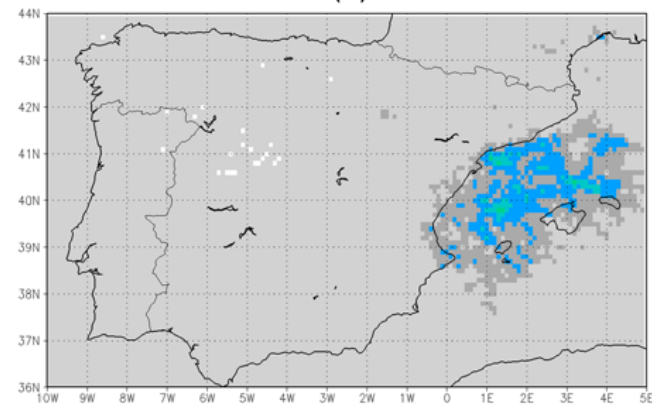

flashes day ${ }^{-1}$

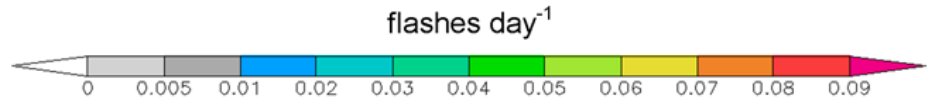

(e)

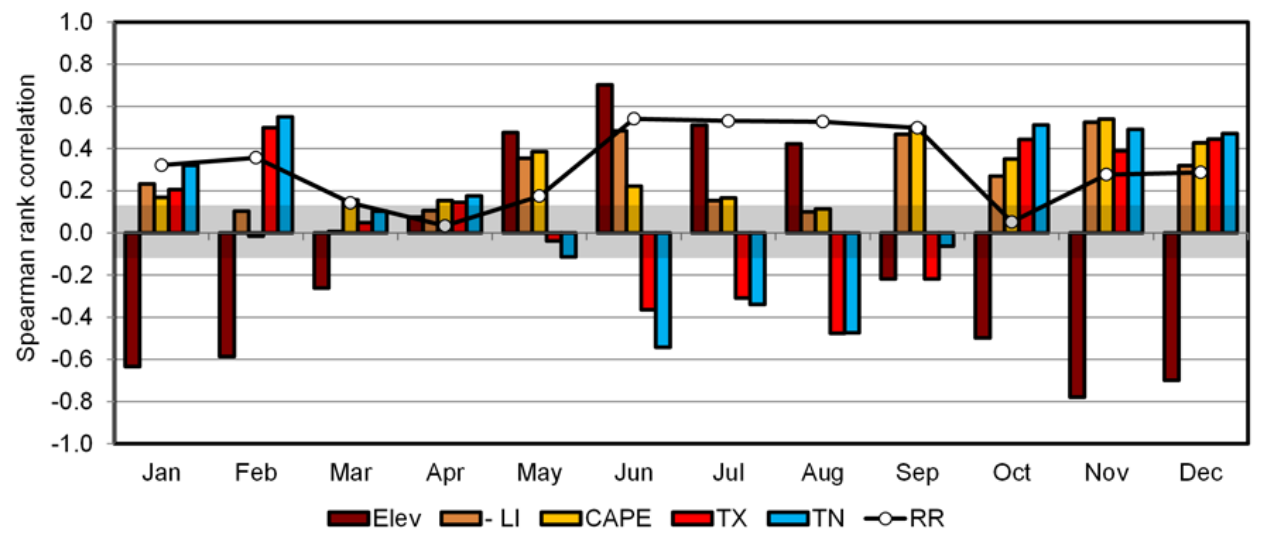

Fig. 5. As in Fig. 4, but only for the positive-polarity CGFs. The same colour scale as in Fig. 4 is also used here.

of positive-polarity CGFs than of total CGFs, resulting in a much more irregular spatial pattern and in lower correlations. As such, there is no clear evidence for differences in the forcing factors of positive- and negative-polarity CGFs. It should be mentioned that positive-polarity CGFs are favoured by other factors, such as wind shear and cloud top heights (Finke and Hauf, 1996), which are not triggering factors of deep convection.

In order to assess the main regional differences amongst the six subsectors (S1-6, Fig. 1), the spatial correlations between the $7 \mathrm{yr}$ means of the monthly CGF occurrences and the corresponding five forcing factors and precipitation are shown in Fig. 6. S6 is not represented in Fig. 6d-f as TN, TX and RR are not available for this sector (E-OBS data only over continental areas). The results for Elev highlight the leading role of the orographically driven thunderstorms in CGF occurrences during the summer half of the year (MaySeptember) and throughout the peninsula (Fig. 6a). The generally lower correlations for $\mathrm{S} 6$ can be explained by the low relevance of the orography in a sector that is mostly at the mean sea level. With respect to LI and CAPE (Fig. 6b-c), there is a clear forcing of lightning activity over most of the peninsula, mainly in the north (S1) and west-central Iberia (S3 and S4) in summer, and in the east (S5) in autumn. 
(a)

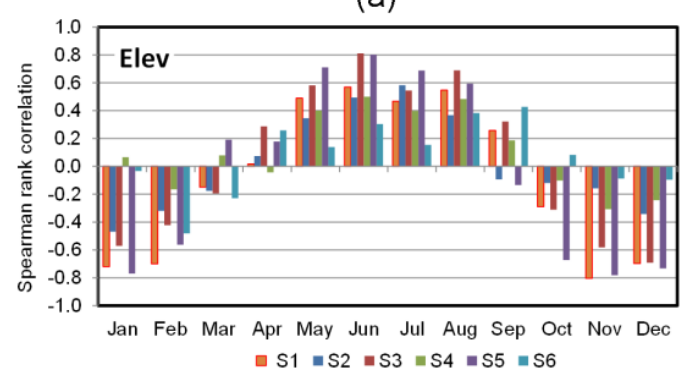

(c)

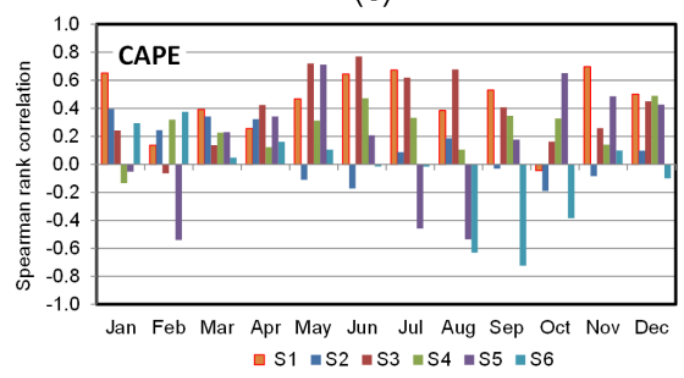

(e)

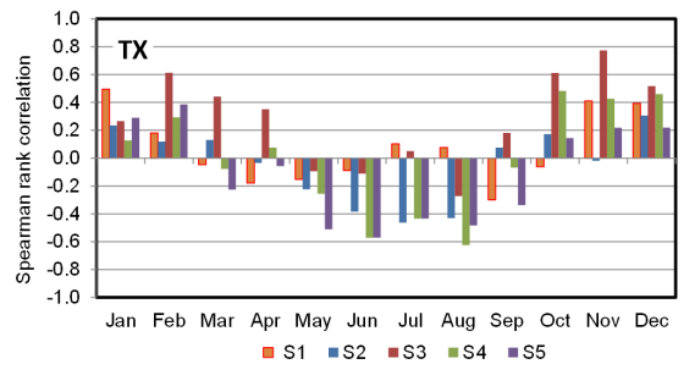

(b)

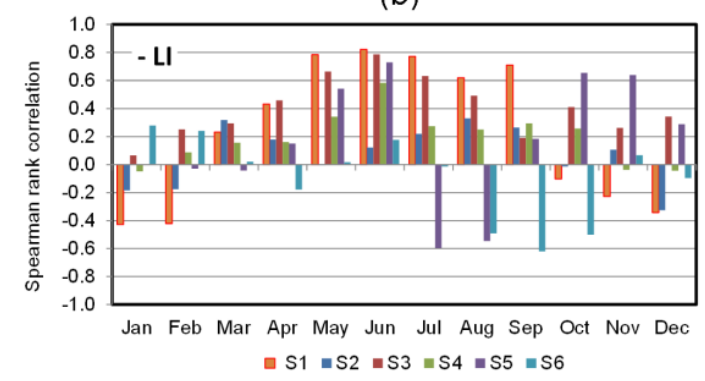

(d)

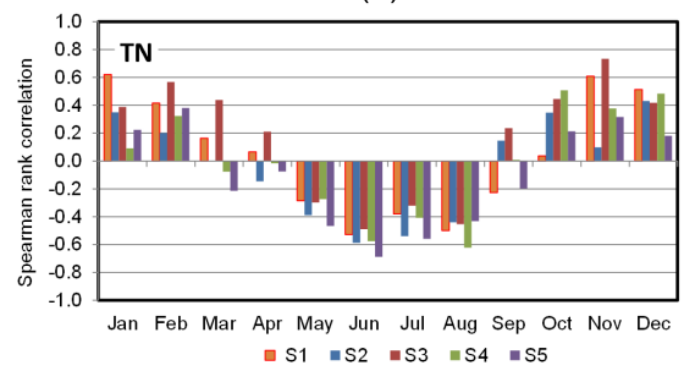

(f)

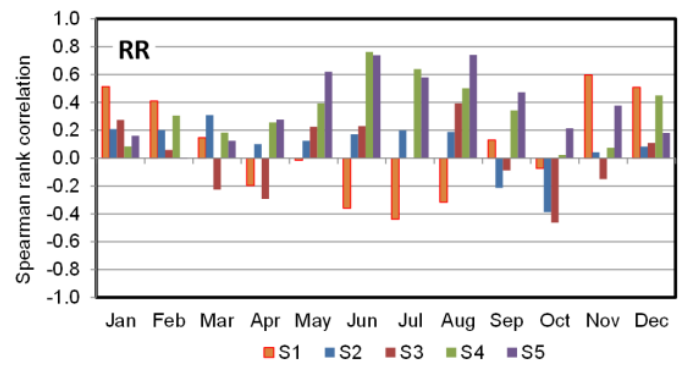

Fig. 6. Spatial Spearman rank correlations between (a) Elev, the 7 yr (2003-2009) monthly means of (b) - LI, (c) CAPE, (d) TN, (e) TX and (f) RR and the corresponding monthly means of the total CGF occurrences for each of the six subsectors (S1-6).

Although these results support previous considerations based on Fig. 4, they also hint at the relevance of the tropospheric buoyancy in triggering summertime lightning activity over western-central and northern Iberia.

In September-October in S6, both CAPE and - LI are negatively correlated with CGFs (Fig. 6b-c). Despite the coherence found between these two indices obtained from two independent data sources, this unexpected result can be partially explained by the coarse grids $\left(1.5^{\circ} \times 1.5^{\circ}\right.$ in CAPE or $1.0^{\circ} \times 1.0^{\circ}$ grid in LI) that are only able to capture largescale features, while subgrid-scale mechanisms are not properly resolved. In this specific case, the maxima of both CAPE and $-\mathrm{LI}$ are located south-eastwards of the maxima CGF occurrences (not shown), which explains the spatial negative correlations. Furthermore, heavy precipitation events with lightning activity in the Mediterranean areas of Iberia have been attributed to low-level instability. In these episodes, instability was not captured by instability indices with upper limits above $500 \mathrm{hPa}$ (as usual), but it emerges when the $700 \mathrm{hPa}$ level is considered (Riesco-Martín et al., 2013). CGF occurrences may also be anomalously large in some rare mesoscale convective systems (as squall lines and supercells). If these systems appear, the statistical results may be altered, especially during autumn in the Mediterranean areas, where intense convective systems are more frequent (Gaya et al., 2001).

The near-surface thermal contrasts (TN and TX) are important from October to February over all of Iberia (Fig. 6de), whereas in the period from May to September the correlations are predominantly negative, which are a reflection of the leading role played by orography. In this latter period, TN and TX are negatively correlated with lightning because flashes tend to occur over mountains at higher altitudes, where temperatures are commonly lower. In addition, CGF occurrences are not always well correlated with lowlevel temperatures, as moisture is also a key factor. Some studies indeed suggest that lightning activity is best related to the wet-bulb temperature (e.g. Reeve and Toumi, 1999), 
which is a proxy for the CAPE (Williams and Renno, 1993). Lastly, the correlations with RR (Fig. 6f) suggest that precipitation is largely related to thunderstorms over central (S4) and eastern Iberia (S5) in May-September, and over northern Iberia (S1) in November-February. While the former relationship is mostly produced by orography and tropospheric buoyancy, the latter can be attributed to cold and unsettled maritime polar air masses that are frequently advected to northern Iberia in winter.

With respect to peak current and multiplicity, their mean patterns are shown in the Supplement. Although the number of positive CGFs is significantly lower than negative CGFs, the seasonal patterns of the mean positive and negative peak currents show that positive are generally higher than negative peak currents for all seasons in the IS (Figs. S1 and S2). The maximum positive and negative peak currents are observed over the peninsula in summer and over nearby water surfaces and coastal areas in winter and autumn, being rather scattered in spring. Lastly, the multiplicity patterns show mean values ranging from 1 to slightly more than 3 (Figs. S3 and S4). Positive CGFs are mainly of unit multiplicity, whilst negative CGFs often show higher multiplicities. This is particularly clear in summer over the peninsula and the adjacent Mediterranean Sea and over the Mediterranean in autumn.

\section{Summary and conclusions}

The CGF characteristics within an Iberian sector (IS: 36$44^{\circ} \mathrm{N}, 10^{\circ} \mathrm{W}-5^{\circ} \mathrm{E}$ ) are analysed using a lightning dataset in the period from 2003 to 2009 ( $7 \mathrm{yr}$ ), based on an Iberian LDN composed of 18 sensors. This innovative dataset allows an integration of the features of lightning activity in Spain and Portugal. Hourly, daily and monthly data of cloud-to-ground flashes, peak current, polarity and multiplicity are analysed on a $0.1^{\circ} \times 0.1^{\circ}$ grid (grid spacing of about $10 \mathrm{~km}$ ) over the IS. The analysis of the temporal variability of CGFs is undertaken for the whole IS and for six non-overlapping subsectors. The $7 \mathrm{yr}$ mean monthly patterns of the number of CGFs are related to five forcing factors (elevation, lifted index, convective available potential energy, and maximum and minimum $2 \mathrm{~m}$ air temperature) and to precipitation.

Regarding the temporal variability, strong seasonal and diurnal cycles are identified, with two maxima in September, peaking at 02:00 and 17:00 UTC, and a secondary maximum in June, in the afternoon. For both the northern sector and the Pyrenees, the analysis shows a preference for CGF occurrences in the warm months (JJA) and in the afternoon. For the western subsector, the strongest activity is found in September, from 16:00 to 18:00 UTC. In central Iberia, two clear maxima are identified (June and September), with maximum CGF occurrences in the afternoon. In eastern Iberia, the lightning activity is mainly in August-September, with strongest incidence during the afternoon. The Balearic Islands sector presents a different pattern when compared to the other subsectors, in view of its maritime climatic characteristics: a predominant peak is identified in September, between 01:00 and 05:00 UTC, and very low activity is found in the afternoon. The influence of the Azores anticyclone in suppressing mid-summer (July) convection is obvious over most of the peninsula. There is no such evidence for the Balearic Islands, where spring activity is indeed very low.

Regarding the spatial variability, the seasonal mean distributions of CGFs in the IS and for each subsector separately suggest they are mainly driven by orographic features in the summer half of the year (May-September), by tropospheric buoyancy in summer (western-central and northern Iberia) and autumn (eastern Iberia), and by near-surface thermal contrasts from October to February. More specifically in winter, the occurrence of lightning activity is comparatively weak over the entire peninsula and mostly located over the Mediterranean Sea, which is supported by the negative correlations with elevation. The near-surface thermal contrasts seem to play a key role in triggering winter lightning. In spring, there is significant but rather scattered lightning activity over the peninsula. However, there is a decrease in the near-surface thermal-contrast forcing and an enhancement of the orographic forcing. In summer, lightning activity is significantly strengthened, with the highest CGF occurrences found over mountainous areas, such as over the Pyrenees and the Iberian mountain range. Secondary peaks are also detected over the Cantabrian and Central mountain ranges. For summer, the orographic and tropospheric buoyancy forcings are clearly prevalent, the latter being particularly clear over western-central and northern Iberia. A weakening of the lightning activity in July is related to the influence of the Azores anticyclone. Finally, in autumn, a shift in the location of the maximum activity area is found, with maxima CGF occurrences over the Mediterranean Sea and the Balearic Islands. For this season, both the near-surface thermal conditions, with high SST in the Mediterranean, and the thermodynamic vertical instability play a crucial role in triggering lightning activity over the Mediterranean regions of Iberia, while the orographically forced lightning is of minor importance for the sector as a whole (negative correlations with elevation). There is also a clear correspondence between the precipitation patterns and the CGF distributions from May to September, mainly in central-eastern Iberia. This result suggests that precipitation in these regions is mostly convective in this period of strong lightning activity.

The spatial distributions of positive-polarity CGFs are similar to the corresponding patterns for total CGFs, but with much lower values. Although the correlations with the forcing factors present quite similar seasonal variability, they are slightly lower than for total CGFs. The patterns of the positive-polarity CGFs are very similar to those obtained for the negative-polarity CGFs (not shown), and there is no clear evidence for differences in their forcing mechanisms. The seasonal patterns of the mean positive and negative peak currents over the IS show that positive peak currents are higher 
than negative peak currents for all seasons. This result is in agreement with previous studies (e.g. Orville and Huffines, 2001; Schulz et al., 2005; Rakov and Uman, 2003). The maximum positive and negative peak currents tend to be observed over the peninsula in summer, and over the neighbouring water bodies in winter and autumn, being largely scattered in spring. Similar results were found by Kumar and Kamra (2012) for South/Southeast Asia. Strong similarities can be found between the multiplicity patterns for positive and negative CGFs with those attained for the peak current. The negative-polarity CGFs tend to present higher multiplicities than the positive-polarity CGFs, which is in agreement with previous studies (e.g. Schulz et al., 2005). Therefore, both peak currents and multiplicity seem to increase when cloud-to-ground (CG) lightning activity and deep convection are at their maxima.

In the present study five forcing factors of lightning activity over Iberia are identified. Additionally, their relevance is discussed by taking seasonality and pronounced spatial heterogeneities into account. The role of other common forcing factors of lightning, such as mid-tropospheric cold-core troughs, upward vertical velocity, vorticity, moist static stability indices and wind, cannot be properly tested with the present study methodology, as the $7 \mathrm{yr}$ time means offset the likely temporal co-variability between them and CGF occurrences. The present study only focuses on spatial correlations between the time means of forcing factors and CGFs. Although an analysis in the time domain may overcome this limitation, it is strongly constrained by the short sample of lightning data $(7 \mathrm{yr})$ that undermines the significance of the results by reflecting only a few lightning episodes. In fact, the CGF series in a given grid box present a large number of zero occurrences (some grid boxes have very few lightning days in the full period) and are highly positively skewed. These properties are important shortcomings for their statistical analysis and require data transformations. On the other hand, the coarse grid resolutions of the datasets used in the present study do not accurately resolve relevant mesoscale (subgrid) processes that are also expected to play an important role in the CGF occurrences. As such, other significant forcing factors of lightning are expected to arise when carrying out an analysis on a daily basis and using high-resolution grids (grid spacing typically $<10 \mathrm{~km}$ ), which can be attained by dynamical downscaling from regional climate model simulations. This fine-resolution analysis may enable the assessment of the role played by mesoscale systems, such as convection cells, fronts and local/regional winds (e.g. breezes). Nevertheless, these assessments are out of the scope of the present study.

After this introductory research, a forthcoming study is projected to develop a statistical modelling of lightning activity over the Iberian Peninsula, subject to the limitations stated above, using multivariate statistical techniques, such as canonical correlation analysis and multivariate regressions, which will be applied to relevant forcing factors. The connections between lightning, thunderstorms and extreme precipitation events over the Iberian Peninsula will also be investigated, mainly the dynamical mechanisms underlying their occurrence, in line with previous studies (Santos et al., 2005, 2007, 2009; Woollings et al., 2011). Due to the still existing difficulties in simulating lightning parameters in regional weather forecasting models (e.g. McCaul et al., 2009; Barthe et al., 2010; Zepka et al., 2013), this analysis could be of utmost relevance to improve our understanding of lightning activity over Iberia and, as a result, the skill of future lightning forecasts.

\section{Supplementary material related to this article is available online at: http://www.nat-hazards-earth-syst-sci.net/13/1745/2013/ nhess-13-1745-2013-supplement.pdf.}

Acknowledgements. The present research is carried out within the project "Lightning activity in Portugal: variability patterns and socioeconomic impacts (RAIDEN)", funded by Fundação para a Ciência e Tecnologia (FCT), PTDC/CTE-ATM/101931/2008. This work is supported by European Union Funds (FEDER/COMPETE - Operational Competitiveness Programme) and by national funds (FCT - Portuguese Foundation for Science and Technology) under the project FCOMP-01-0124-FEDER-022692. The authors also acknowledge the Portuguese Meteorological Office (IPMA), for providing the Portuguese lightning dataset under a protocol established within the framework of the RAIDEN project, and the Spanish Meteorological Agency (AEMET), for supplying the Spanish lightning dataset. The authors also acknowledge the EUFP6 project ENSEMBLES (http://ensembles-eu.metoffice.com) and the ECA\&D project (http://eca.knmi.nl) for providing the E-OBS dataset, and the University Corporation for Atmospheric Research (UCAR) for providing their best 4-layer lifted index. The authors are also grateful to the reviewers of this manuscript for their valuable comments and suggestions.

Edited by: G. Panegrossi

Reviewed by: W. Schulz and one anonymous referee

\section{References}

Altaratz, O., Levin, Z., Yair, Y., and Ziv, B.: Lightning activity over land and sea on the eastern coast of the Mediterranean, Mon. Weather Rev., 131, 2060-2070, doi:10.1175/15200493(2003)131<2060:Laolas>2.0.Co;2, 2003.

Barthe, C., Deierling, W., and Barth, M. C.: Estimation of total lightning from various storm parameters: A cloudresolving model study, J. Geophys. Res.-Atmos., 115, D24202, doi:10.1029/2010jd014405, 2010.

Barthlott, C., Corsmeier, U., Meissner, C., Braun, F., and Kottmeier, C.: The influence of mesoscale circulation systems on triggering convective cells over complex terrain, Atmos. Res., 81, 150-175, doi:10.1016/j.atmosres.2005.11.010, 2006.

Carleton, A. M., Arnold, D. L., Travis, D. J., Curran, S., and Adegoke, J. O.: Synoptic circulation and land surface influences on 
convection in the Midwest US "Corn Belt" during the summers of 1999 and 2000, Part I: Composite synoptic environments, J. Climate, 21, 3389-3415, doi:10.1175/2007jcli1578.1, 2008.

Carvalho, R., Prior, V., and Deus, R.: Exploração experimental do sistema rede de detetores de trovoadas, $3^{\circ}$ Simpósio de Meteorologia e Geofísica Aveiro, Portugal, 2003, p. 36, 2003.

Christian, H. J., Blakeslee, R. J., Boccippio, D. J., Boeck, W. L., Buechler, D. E., Driscoll, K. T., Goodman, S. J., Hall, J. M., Koshak, W. J., Mach, D. M., and Stewart, M. F.: Global frequency and distribution of lightning as observed from space by the Optical Transient Detector, J. Geophys. Res.-Atmos., 108, 4005, doi:10.1029/2002jd002347, 2003.

Cohuet, J. B., Romero, R., Homar, V., Ducrocq, V., and Ramis, C.: Initiation of a severe thunderstorm over the Mediterranean Sea, Atmos Res, 100, 603-620, doi:10.1016/j.atmosres.2010.11.002, 2011.

Corsmeier, U., Kalthoff, N., Barthlott, C., Aoshima, F., Behrendt, A., Di Girolamo, P., Dorninger, M., Handwerker, J., Kottmeier, C., Mahlke, H., Mobbs, S. D., Norton, E. G., Wickert, J., and Wulfmeyer, V.: Processes driving deep convection over complex terrain: a multi-scale analysis of observations from COPS IOP 9c, Q. J. Roy. Meteorol. Soc., 137, 137-155, doi:10.1002/qj.754, 2011.

Cummins, K. L., Murphy, M. J., Bardo, E. A., Hiscox, W. L., Pyle, R. B., and Pifer, A. E.: A combined TOA/MDF Technology Upgrade of the US National Lightning Detection Network, J. Geophys. Res.-Atmos., 103, 9035-9044, doi:10.1029/98jd00153, 1998.

Dee, D. P., Uppala, S. M., Simmons, A. J., Berrisford, P., Poli, P., Kobayashi, S., Andrae, U., Balmaseda, M. A., Balsamo, G., Bauer, P., Bechtold, P., Beljaars, A. C. M., van de Berg, L., Bidlot, J., Bormann, N., Delsol, C., Dragani, R., Fuentes, M., Geer, A. J., Haimberger, L., Healy, S. B., Hersbach, H., Holm, E. V., Isaksen, L., Kallberg, P., Kohler, M., Matricardi, M., McNally, A. P., Monge-Sanz, B. M., Morcrette, J. J., Park, B. K., Peubey, C., de Rosnay, P., Tavolato, C., Thepaut, J. N., and Vitart, F.: The ERA-Interim reanalysis: configuration and performance of the data assimilation system, Q. J. Roy. Meteorol. Soc., 137, 553597, doi:10.1002/Qj.828, 2011.

De Pablo, F. and Soriano, L. R.: Relationship between cloudto-ground lightning flashes over the Iberian Peninsula and sea surface temperature, Q. J. Roy. Meteorol. Soc., 128, 173-183, doi:10.1256/00359000260498842, 2002.

De Pablo, F. and Soriano, L. R.: Winter lightning and north Atlantic oscillation, Mon. Weather Rev., 135, 2810-2815, doi:10.1175/Mwr3429.1, 2007.

de Souza, P. E., Pinto, O., Pinto, I. R. C. A., Ferreira, N. J., and dos Santos, A. F.: The intracloud/cloud-to-ground lightning ratio in Southeastern Brazil, Atmos. Res., 91, 491-499, doi:10.1016/j.atmosres.2008.06.011, 2009.

Dissing, D. and Verbyla, D. L.: Spatial patterns of lightning strikes in interior Alaska and their relations to elevation and vegetation, Can. J. Forest. Res., 33, 770-782, doi:10.1139/X02-214, 2003.

Enno, S. E.: A climatology of cloud-to-ground lightning over Estonia, 2005-2009, Atmos. Res., 100, 310-317, doi:10.1016/j.atmosres.2010.08.024, 2011.

Fankhauser, J. C., Crook, N. A., Tuttle, J., Miller, L. J., and Wade, C. G.: Initiation of Deep Convection Along Boundary-Layer Convergence Lines in a Semitropical Environ- ment, Mon. Weather Rev., 123, 291-313, doi:10.1175/15200493(1995)123<0291:Iodcab>2.0.Co;2, 1995.

Finke, U. and Hauf, T.: The characteristics of lightning occurrence in southern Germany, Beitr. Phys. Atmos., 69, 361-374, 1996.

Founda, D., Tombrou, M., Lalas, D. P., and Asimakopoulos, D. N.: Some measurements of turbulence characteristics over complex terrain, Bound.-Lay. Meteorol., 83, 221-245, doi:10.1023/A:1000288002105, 1997.

Gaya, M., Homar, V., Romero, R., and Ramis, C.: Tornadoes and waterspouts in the Balearic Islands: phenomena and environment characterization, Atmos. Res., 56, 253-267, doi:10.1016/S01698095(00)00076-4, 2001.

Gladich, I., Gallai, I., Giaiotti, D. B., and Stel, F.: On the diurnal cycle of deep moist convection in the southern side of the Alps analysed through cloud-to-ground lightning activity, Atmos. Res., 100, 371-376, doi:10.1016/j.atmosres.2010.08.026, 2011.

Hanesiak, J. M., Raddatz, R. L., and Lobban, S.: Local initiation of deep convection on the Canadian prairie provinces, Bound.-Lay. Meteorol., 110, 455-470, doi:10.1023/B:Boun.0000007242.89023.E5, 2004.

Haylock, M. R., Hofstra, N., Tank, A. M. G. K., Klok, E. J., Jones, P. D., and New, M.: A European daily highresolution gridded data set of surface temperature and precipitation for 1950-2006, J. Geophys. Res.-Atmos., 113, D20119, doi:10.1029/2008jd010201, 2008.

Hidayat, S. and Ishii, M.: Spatial and temporal distribution of lightning activity around Java, J. Geophys. Res.-Atmos., 103, 1400114009, doi:10.1029/97jd01576, 1998.

Holton, J. R.: An Introduction to Dynamic Meteorology, edited by: Cynar, F., Elsevier, USA, 2004.

Homar, V., Gaya, M., Romero, R., Ramis, C., and Alonso, S.: Tornadoes over complex terrain: an analysis of the 28th August 1999 tornadic event in eastern Spain, Atmos. Res., 67-8, 301-317, doi:10.1016/S0169-8095(03)00064-4, 2003.

Kalthoff, N., Adler, B., Barthlott, C., Corsmeier, U., Mobbs, S., Crewell, S., Traumner, K., Kottmeier, C., Wieser, A., Smith, V., and Di Girolamo, P.: The impact of convergence zones on the initiation of deep convection: A case study from COPS, Atmos. Res., 93, 680-694, doi:10.1016/j.atmosres.2009.02.010, 2009.

Kilinc, M. and Beringer, J.: The spatial and temporal distribution of lightning strikes and their relationship with vegetation type, elevation, and fire sears in the Northern Territory, J. Climate, 20, 1161-1173, doi:10.1175/Jcli4039.1, 2007.

Kumar, P. R. and Kamra, A. K.: Lightning activity variations over three islands in a tropical monsoon region, Atmos. Res., 98, 309316, doi:10.1016/j.atmosres.2010.07.014, 2010.

Kumar, P. R. and Kamra, A. K.: Land-sea contrast in lightning activity over the sea and peninsular regions of South/Southeast Asia, Atmos. Res., 118, 52-67, doi:10.1016/j.atmosres.2012.05.027, 2012.

Kunz, M.: The skill of convective parameters and indices to predict isolated and severe thunderstorms, Nat. Hazards Earth Syst. Sci., 7, 327-342, doi:10.5194/nhess-7-327-2007, 2007.

Kunz, M. and Wassermann, S.: Sensitivity of flow dynamics and orographic precipitation to changing ambient conditions in idealised model simulations, Meteorol. Z., 20, 199-215, doi:10.1127/0941-2948/2011/0221, 2011.

Leite, S. and Santos, J. A.: Contribution to the Analysis of Iberian Peninsula Climate Variability, General Assembly of the Euro- 
pean Geophysical Society, Nice, France, April 1998, C 701, 1998.

McCaul, E. W., Goodman, S. J., LaCasse, K. M., and Cecil, D. J.: Forecasting Lightning Threat Using CloudResolving Model Simulations, Weather Forecast., 24, 709-729, doi:10.1175/2008waf2222152.1, 2009.

Orville, R. E. and Huffines, G. R.: Lightning ground flash measurements over the contiguous United States: 199597, Mon. Weather Rev., 127, 2693-2703, doi:10.1175/15200493(1999)127<2693:Lgfmot > 2.0.Co;2, 1999.

Orville, R. E. and Huffines, G. R.: Cloud-to-ground lightning in the United States: NLDN results in the first decade, 198998, Mon. Weather Rev., 129, 1179-1193, doi:10.1175/15200493(2001)129<1179:Ctglit>2.0.Co;2, 2001.

Orville, R. E., Zipser, E. J., Brook, M., Weidman, C., Aulich, G., Krider, E. P., Christian, H., Goodman, S., Blakeslee, R., and Cummins, K.: Lightning in the region of the TOGA COARE, B. Am. Meteorol. Soc., 78, 1055-1067, doi:10.1175/15200477(1997)078<1055:Litrot>2.0.Co;2, 1997.

Peixoto, J. P. and Oort, A. H.: Physics of Climate, American Institute of Physics, New York, USA, 1992.

Pérez-Puebla, F.: Cooperación entre las redes de rayos de España y Portugal, Jornadas Científicas de la Asociación Meteorológica de España, Badajoz, Spain, 2004, p. 10, 2004.

Pielke, R. A.: Influence of the spatial distribution of vegetation and soils on the prediction of cumulus convective rainfall, Rev. Geophys., 39, 151-177, doi:10.1029/1999rg000072, 2001.

Pinto, J. G., Ulbrich, S., Parodi, A., Rudari, R., Boni, G., and Ulbrich, U.: Identification and ranking of extraordinary rainfall events over Northwest Italy: The role of Atlantic moisture, J. Geophys. Res. Atmos., 118, 2085-2097, doi:10.1002/jgrd.50179, 2013.

Pinto, O. and Pinto, I. R. C. A.: On the sensitivity of cloudto-ground lightning activity to surface air temperature changes at different timescales in Sao Paulo, Brazil, J. Geophys. Res.Atmos., 113, D20123, doi:10.1029/2008jd009841, 2008.

Poelman, D. R.: On the science of lightning: a review, Publication scientifique et technique No 56, Royal Meteorological Institute of Belgium, 2010.

Rakov, V. A. and Uman, M. A.: Lightning, physics and effects, Cambridge University Press, Cambridge, UK, 687 pp., 2003.

Ramos, A. M., Ramos, R., Sousa, P., Trigo, R. M., Janeira, M., and Prior, V.: Cloud to ground lightning activity over Portugal and its association with circulation weather types, Atmos. Res., 101, 84-101, doi:10.1016/j.atmosres.2011.01.014, 2011.

Raymond, D. and Wilkening, M.: Mountain-Induced Convection under Fair Weather Conditions, J. Atmos. Sci., 37, 2693-2706, doi:10.1175/1520-0469(1980)037<2693:Micufw>2.0.Co;2, 1980.

Reeve, N. and Toumi, R.: Lightning activity as an indicator of climate change, Q. J. Roy. Meteorol. Soc., 125, 893-903, doi:10.1256/Smsqj.55506, 1999.

Riesco Martín, J., Mora García, M., De Pablo Dávila, F., and Rivas Soriano, L.: Severe rainfall events over the western Mediterranean Sea: A case study, Atmos. Res., 127, 47-63, doi:10.1016/j.atmosres.2013.03.001, 2013.

Rodrigues, R. B., Mendes, V. M. F., Catalao, J. P. S., Correia, S., Prior, V., and Aguado, M.: An Investigation over the Lightning Location System in Portugal for Wind Turbine Protection Devel- opment, Conference: Power and Energy Society General Meeting - Conversion and Delivery of Electrical Energy in the 21st Century, 2008 IEEE, Ieee Pow. Ener. Soc. Ge., 2324-2331, 2008.

Rodrigues, R. B., Mendes, V. M. F., and Catalao, J. P. S.: Lightning Data Observed With Lightning Location System in Portugal, Ieee T. Power. Deliver., 25, 870-875, doi:10.1109/Tpwrd.2009.2037325, 2010.

Romero, R., Sumner, G., Ramis, C., and Genoves, A.: A classification of the atmospheric circulation patterns producing significant daily rainfall in the Spanish Mediterranean area, Int. J. Climatol., 19, 765-785, doi:10.1002/(Sici)10970088(19990615)19:7<765::Aid-Joc388>3.0.Co;2-T, 1999.

Rozoff, C. M., Cotton, W. R., and Adegoke, J. O.: Simulation of St. Louis, Missouri, land use impacts on thunderstorms, J. Appl. Meteorol., 42, 716-738, doi:10.1175/15200450(2003)042<0716:Soslml>2.0.Co;2, 2003.

Santos, J. A. and Mendes, A. R.: Atmospheric forcing in the occurrence of precipitation extremes in Iberia: comparison between the eastern and western sectors, European Meteorological Society Annual Meeting, Toulouse, France, October 2009, EMS2009-2178-2001, 2009.

Santos, J. A. and Santos, M.: Extreme precipitation events in Iberia: a synoptic viewpoint, International Conference on Ecohydrology and Climate Change, Tomar, Portugal, September 2009, p. 124, 2009.

Santos, J. A., Corte-Real, J., and Leite, S. M.: Weather regimes and their connection to the winter rainfall in Portugal, Int. J. Climatol., 25, 33-50, doi:10.1002/joc.1101, 2005.

Santos, J. A., Corte-Real, J., Ulbrich, U., and Palutikof, J.: European winter precipitation extremes and large-scale circulation: a coupled model and its scenarios, Theor. Appl. Climatol., 87, 85102, doi:10.1007/s00704-005-0224-2, 2007.

Santos, J. A., Pinto, J. G., and Ulbrich, U.: On the development of strong ridge episodes over the eastern North Atlantic, Geophys. Res. Lett., 36, L17804, doi:10.1029/2009g1039086, 2009.

Santos, J. A., Reis, M. A., Sousa, J., Leite, S. M., Correia, S., Janeira, M., and Fragoso, M.: Cloud-to-ground lightning in Portugal: patterns and dynamical forcing, Nat. Hazards Earth Syst. Sci., 12, 639-649, doi:10.5194/nhess-12-639-2012, 2012.

Schulz, W., Diendorfer, G., Hofbauer, F., and Stimmer, A.: Correction of lightning density and lightning current distributions for detection efficiency trigger level of the DF Saturation limit of the DF, International Conference on Lightning Protection, Florence, Italy, September 1996, p. 6, 1996.

Schulz, W., Diendorfer, G., Hofbauer, F., Stimmer, A., and Mair, M.: Site errors in magnetic direction finding due to buried cables, International Conference on Lightning Protection, Birmingham, England, September 1998, p. 6, 1998.

Schulz, W., Cummins, K., Diendorfer, G., and Dorninger, M.: Cloud-to-ground lightning in Austria: A 10-year study using data from a lightning location system, J. Geophys. Res.-Atmos., 110, D09101, doi:10.1029/2004jd005332, 2005.

Soriano, L. J. R., De Pablo, F., and Diez, E. L. G.: Meteorological and geo-orographical relationships with lightning activity in Castilla-Leon (Spain), Meteorol. Appl., 8, 169-175, 2001a.

Soriano, L. R., De Pablo, F., and Diez, E. G.: Relationship between convective precipitation and cloud-to-ground lightning in the Iberian Peninsula, Mon. Weather Rev., 129, 2998-3003, doi:10.1175/1520-0493(2001)129<2998:Rbcpac > 2.0.Co;2, 
$2001 b$.

Soriano, L. R. and De Pablo, F.: Maritime cloud-to-ground lightning: The western Mediterranean Sea, J. Geophys. Res.-Atmos., 107, 4597, doi:10.1029/2002jd002211, 2002.

Soriano, L. R., De Pablo, F., and Tomas, C.: Impact of the North Atlantic oscillation on winter convection: Convective precipitation and cloud-to-ground lightning, Int. J. Climatol., 24, 1241-1247, doi:10.1002/Joc.1067, 2004.

Soriano, L. R., De Pablo, F., and Tomas, C.: Ten-year study of cloud-to-ground lightning activity in the Iberian Peninsula, J. Atmos. Sol.-Terr. Phys., 67, 1632-1639, doi:10.1016/j.jastp.2005.08.019, 2005.

Steiger, S. M., Hamilton, R., Keeler, J., and Orville, R. E.: LakeEffect Thunderstorms in the Lower Great Lakes, J. Appl. Meteorol. Climatol., 48, 889-902, doi:10.1175/2008jamc1935.1, 2009.

Stein, J.: Exploration of some convective regimes over the Alpine orography, Q. J. Roy. Meteorol. Soc., 130, 481-502, doi:10.1256/Qj.02.220, 2004.

Tian, W. S. and Parker, D. J.: Two-dimensional simulation of orographic effects on mesoscale boundary-layer convection, Q. J. Roy. Meteorol. Soc., 128, 1929-1952, doi:10.1256/003590002320603476, 2002.

Tinmaker, M. I. R., Ali, K., and Beig, G.: Relationship between Lightning Activity over Peninsular India and Sea Surface Temperature, J. Appl. Meteorol. Climatol., 49, 828-835, doi:10.1175/2009jamc2199.1, 2010.
Tomas, C., De Pablo, F., and Soriano, L. R.: Circulation weather types and cloud-to-ground flash density over the Iberian Peninsula, Int. J. Climatol., 24, 109-123, doi:10.1002/Joc.917, 2004.

Toth, J. J. and Johnson, R. H.: Summer Surface Flow Characteristics over Northeast Colorado, Mon. Weather Rev., 113, 1458-1469, doi:10.1175/1520-0493(1985)113<1458:Ssfcon>2.0.Co;2, 1985.

Wilks, D. S.: Statistical methods in the atmospheric sciences, 2nd Edn., International geophysics series, 91, Academic Press, Amsterdam, Boston, xvii, 627 pp., 2011.

Williams, E. and Renno, N.: An Analysis of the Conditional Instability of the Tropical Atmosphere, Mon. Weather Rev., 121, 2136, doi:10.1175/1520-0493(1993)121<0021:Aaotci>2.0.Co;2, 1993.

Woollings, T., Pinto, J. G., and Santos, J. A.: Dynamical Evolution of North Atlantic Ridges and Poleward Jet Stream Displacements, J. Atmos. Sci., 68, 954-963, doi:10.1175/2011jas3661.1, 2011.

Zepka, G. S., Pinto Jr., O. and Saraiva, A. C. V.: Lightning forecasting in southeastern Brazil using the WRF model, Atmos. Res., doi:10.1016/j.atmosres.2013.01.008, in press, 2013. 